\title{
Research on Affordable Housing Based on Supply Side Reform
}

\author{
Zou Li, Xv Junjie \\ Logistics University of PAP
}

\begin{abstract}
With the acceleration of urbanization and population mobility in recent years, the problem of housing contradictions has become increasingly prominent. The government and relevant departments are also constantly exploring new development models for innovative affordable housing to solve a large number of housing needs. Against the background of supply-side structural reform, this paper summarizes the five problems in the construction operation of affordable housing from the perspective of supply, that is, the contradiction between demand rigidity and supply tension, the construction standards are not implemented, Living space differentiation hinders urban integration, the supporting facilities are backward and lower the quality of housing, the safe housing audit operation is not standardized. Finally the paper proposes relevant countermeasures.
\end{abstract}

Keywords-Supply side; Affordable housing; Countermeasures

\section{INTRODUCTION}

Over the past 30 years of reform and opening up, under the correct leadership of the party and the government, China's economic construction has achieved remarkable achievements. The national wealth has been greatly enriched. People's material living standards and cultural living standards have been greatly improved. However, we must be soberly aware that our well-off society is still preliminary and the material living standards of people across the country are still very uneven. Because China's special national conditions, as well as the policy of reform and opening up, on the basis of balancing fairness and efficiency, let some people get rich first and finally achieve common prosperity. However, due to the imbalance of resource allocation, policy inclination and geographical advantages in coastal areas, domestic society inevitably has a situation of polarization between rich and poor. It has become more and more fierce, causing a series of social problems. In recent years, the contradiction between housing supply and demand in major cities has received more and more attention from all walks of life.

For the urban housing supply and demand system, the needs of people in different classes are different for housing. First of all, for the elite class of the society, the minority class belonging to the society has a huge social wealth and is the actual consumer of high-end housing. Secondly, for those who belong to government officials, civil servants and employees of state enterprises and institutions, because they enjoy the inclination of national policies and the generous social welfare, it is easy to purchase housing that meets their expectations. In contrast, in the process of urbanization in China, a large number of rural surplus labor force in the city are the backbone of urban construction and have made an indelible contribution to the rapid development of the city. However, due to the hukou system, they are unable to enjoy local preferential policies. These blue-collar workers with low academic qualifications can only earn a living by selling labor. They still cannot purchase a satisfactory housing because of meager wages. In the same way, some of the hard-working people who live on the subsistence allowances issued by the government can only face the high prices in the city and silently sigh. Living in the bottom of the social class, they need the government to provide low-rent housing with social welfare to solve the housing difficulties. In addition, for some groups that are neither low-income nor high-income, such as the newly graduated university students in the city, because they have just entered the society and can't afford the high renting costs. They are also facing the distress of finding it difficult to find a suitable housing.

With the process of marketization, the housing problem has received increasing attention from people. According to $\mathrm{Mr}$. Xi's position that "the house is used for living, not for speculation", the state has accelerated the establishment of a multi-subject supply and a multi-channel housing system. Guaranteed housing security is an important way to achieve housing demand for low- and middle-income groups, and is an important part of social and people's livelihood construction. In recent years. The problem of the gap between the rich and the poor has become more apparent through the carrier of housing. Under the background of deepening the structural reform of the supply side, the means of regulation gradually shifted from the demand side to the supply side and it is particularly important to improve the supply efficiency and quality of affordable housing.

\section{PROBLEMS IN THE MANAGEMENT OF AFFORDABLE HOUSING}

\section{A. Contradiction between demand rigidity and supply tension}

First, the demand for rigidity increases. In recent years, with the continuous improvement of China's welfare and social security, the housing security targets stipulated by the system have been continuously enriched and expanded, and migrant workers, graduates and relocated households have been included in the protection target [1]. Coupled with the process of urbanization and the steady pace of population movement to 
the city, a large number of residents and temporary population in the city have imposed enormous rigid demand for housing security.

Second, the supply is tight and the structure is unreasonable. According to the statistics of the National Bureau of Statistics, by the end of 2016, 36 million sets of urban security housing projects have been completed in the past five years. However, among all the affordable housing, the type of shantytown transformation is far more than other types of affordable housing with an average proportion of $60 \%-70 \%$. The unreasonable supply structure has led to insufficient capacity for affordable housing to absorb the real low-income groups, especially the ability of absorbing the non-urban householding "insurance" group.

\section{B. Construction standards are not implemented, resulting in increased costs}

According to the spirit of state issue [2007] No. 24 document, the affordable housing strictly controls the size of the casing. The affordable area for affordable housing is 60 square meters of building area and if the family members are 3 or more, the guaranteed area is 80 square meters [2]. Although the regulations have already made clear specifications, due to the lack of mandatory restrictions, there are still many areas that expand the number of affordable housing units and the construction standards are getting higher and higher. The affordable housing tends to have the characteristics of some commercial housing. In addition, in the regulations on the construction of affordable housing, the sales price of affordable housing must be maintained within a certain reasonable range. However, in order to maximize profits, many real estate developers often touch the edge of the system, take high or not and even profit by raising the selling price. Not only that, because the continuous improvement of the market price of commercial housing, the price of input factors for building houses, such as land and building materials, has also risen and the cost of building affordable housing is increasing.

\section{Living space differentiation hinders urban integration}

The affordable housing is made for public welfare purposes whose construction is restricted by funds and the location is mostly remote from the city center. The affordable housing will not affect the sustainable development of the urban commercial housing market. Most of the households' work places are in the urban area which causes prominent problems in the separation of the work place and the place of residence and imposes objective conditions on the choice of employment for some people. Since affordable housing is often concentrated on a large-scale construction in a certain area, the living space of residents and ordinary residents who enjoy affordable housing is intensified. A large number of low-income people gather in one area to form a "slum" in the city. It also adds hidden dangers to the stability of society [3]. People who enjoy social welfare in this environment are more likely to deepen their incorrect understanding of the polarization between the rich and the poor which may lead to dissatisfaction and opposition to certain social inequities and bring negative Effects to personal growth and urban development.

\section{Supporting facilities are backward and lower the quality of housing}

The outstanding performance of the low level of affordable housing construction is that the corresponding transportation, commerce, education and other supporting facilities are backward or even lacking which brings great inconvenience to the daily life and employment of the residents. On the one hand, the performance of transportation facilities is lagging behind. Safe housing is more common in places far from the working point, the working point is concentrated in the city center and the residential area is concentrated in several suburbs. The problem brought about by intensive work and living areas is that during the peak period of commuting. A large number of people are moving in the same direction. In addition, the area of affordable housing is not as developed as the urban area which brings great pressure on traffic. On the other hand, the living facilities are not perfect. The infrastructure conditions at the edge of the city were originally weak. The nearby medical care, education and entertainment were less likely to be built because they could not obtain more profit, thus increasing the cost of living for residents. Due to the limited consumption capacity of low- and middle-income people, large-scale public service facilities fail to meet the prescribed "lowest threshold" which is unwilling to re-layout. It also causes many commercial facilities to be idle, eventually forming a vicious circle.

\section{E. Safe housing audit operation is not standardized}

The important reason for the non-standardization of the object of affordable housing is that the object orientation is rather vague, especially in the issue of the protection of affordable housing. First of all, the applicants for affordable housing are low- and middle-income groups, while the range of low- and middle-income people is relatively broad and it is difficult for the government to accurately assess the applicant's assets. Such malpractice has caused many people who are not satisfied with the purchase of housing to lie into the lowincome group of individuals in order to obtain the value-added income of the affordable housing and crowd out the middlelow income class that really needs housing. Secondly, there is no clear norm on the mechanism for withdrawing from the guarantee [4]. Frequent disputes and compensations when the security object exits the affordable housing often lead to a low sustainable utilization rate of the affordable housing.

\section{SUGGESTIONS ON IMPROVING THE MANAGEMENT OF AFFORDABLE HOUSING}

\section{A. Supply based on demand}

First, improve the system of shared property houses. At present, China has begun to implement the method of shared property housing as an innovative model for affordable housing. It has been piloted in many provinces and cities and will be widely implemented throughout the country. Under this model, the government and the buyers jointly own property rights and the government often holds $30 \%$ or $50 \%$ of the property rights. Buyers have permanent residency rights and can sell their homes at market prices to obtain the benefits of their own property rights. This policy has eased the pressure on 
government investment and encouraged more applicants with certain economic conditions to purchase houses. However, the current shareholding housing system is still not perfect. The corresponding housing security and supporting policies have not been fully followed, which has brought certain inconvenience to the residents of the shared property housing. It is necessary for the government and relevant departments to timely supplement the sound policy system.

Second, learn from the PPP model. Learning the PPP model of developed countries, the government and local enterprises establish cooperative relations and absorb social enterprises to participate in the construction of affordable housing. The government gives them preferential policies on investment and financing and taxation. Since affordable housing is of a social welfare nature, and the nature of capital is the pursuit of profit maximization, the restriction of income leads to the failure of traditional real estate development financing in this field. The proportion of local investment enterprises in economic and social benefits must be weighed from the mechanism design and a new model of housing financing system should be explored. At present, the income that the investment enterprise obtains from the affordable housing is mainly from the sales profit and is limited to the government to control the price. This part of the profit cannot have too much room for improvement. Investment companies should expand the profit channel to the later operating profit to compensate for the previous development costs.

\section{B. Reasonable planning to reduce costs}

In the case of a general increase in production factors in the housing market, in addition to the use of state control measures to reduce the cost of land, building materials and other factors, it is more important to use limited resources reasonably and efficiently [5]. At present, China's legal policy has established strict space type and area standards for affordable housing. Generally, the area of use per household is 50-60 square meters. In accordance with the provisions of the construction of affordable housing, not maliciously expand the area of affordable housing for profit, comprehensive screening and rectification of the country's substandard housing to truly achieve the purpose of safeguard housing.

In addition, because the profitable space of affordable housing is smaller than that of commercial housing, developers often hold the concept of low cost and low standard. They will not conduct in-depth research and development on small-sized houses, but generally simple and extensive design. The spatial planning of many affordable housing is unreasonable which affects the quality of life of residents and invisible waste of resources. For the sake of long-term development, affordable housing should be built into a quality project that not only ensures the rationality and comfort of the housing but also builds it into a landscape of the city. Before the construction of affordable housing, it is necessary to rationally design the overall spatial layout and indoor planning according to the needs of different groups and the characteristics of small-sized houses and make full use of the scarce land resources. The energy-saving design of houses is also a part that must be considered in the current energy shortage of society. In the various aspects of the design and construction of affordable housing, the concept of "energy saving" and "environmental protection" is integrated and green materials are saved from material selection to energy utilization.

\section{Destocking to promote integration}

At present, the legal level only has a policy of public housing rental which is a kind of affordable housing. More comprehensive measures are needed to realize the all-round construction model. China should absorb foreign experience and implement the mode of mixed living requiring developers to additionally allocate some properties in the developed commercial housing to change their functions to affordable housing for use, not only in public rental housing, but also to realize commercial housing and affordable housing. In a certain living space of the city, the different groups of people are artificially combined to reduce the spatial differentiation. This is also the new planning concept of "community mix, neighborhood homogeneity" that academic circles called. The phenomenon of "village in the city" formed by the concentration of sex housing has alleviated the psychological pressure of the insured residents and promoted the stable development of society.

In addition, we can learn from the Australian experience, change the operating model of the transfer of government housing management and establish a model for developers to participate in operations. The government can give management rights to some of the affordable housing. The developer can transform the commercial housing that has not been sold into a guaranteed housing within a certain period of time and hold its property rights. It can provide rental services to the guaranteed population according to the governmentlimited price and continue to choose to place the commercial housing market transaction after the lease expires. Since the quality of the leased houses and the post-sales are all the responsibility of the developers themselves, the government's capital investment and management pressure can be alleviated.

\section{Improve the quality of facilities}

In addition to the need to consider the housing itself, affordable housing should also improve living facilities. One of the first areas of concern is travel. For the middle and low income groups, due to the consideration of savings and later spending, the common way of travel is public transportation facilities. Therefore, on the issue of site selection, affordable housing should be selected in the vicinity of the city's main streets, subways or rail transit to save traffic costs with convenient traffic conditions and to facilitate the realization of basic needs such as commuting and shopping.

Secondly, education, medical care, commerce and other industries supporting construction should be in a timely manner. In order to bring a better life experience to residents and meet the diverse needs of life, we can learn from the development model of Singapore's "new town". The new town will use half of the land for the construction of public facilities such as food courts, kindergartens, hospitals and shopping malls. On the one hand, the improvement of supporting facilities has reduced residents' dependence on transportation and on the other hand, it has brought great convenience to residents' lives. Therefore, to a certain extent, the most important thing for the location 
planning of affordable housing is not the distance from the city center, but whether it can establish a large community in the residential area to achieve all-round development.

\section{E. Relying on big data regulation}

First, improve the unified qualification review system for affordable housing. The system corresponds to different types of affordable housing according to the applicant's economic and asset status. On the platform of affordable housing information, the real-time examination and approval of affordable housing across the country will be announced to facilitate the supervision of the masses and departments at any time. Secondly, the personal credit file should be established as soon as possible and the effective information of the credit record department, such as public security, banking, taxation should be sorted and shared into the personal credit system, and the qualifications for the applicants of the affordable housing should be consistent.

Second, improve the exit system of affordable housing. Residents applying for withdrawal from affordable housing submit information in the system. The system uses big data combined with information on affordable housing standards and personal credit files on the information platform to automatically process data and make approval opinions, thereby simplifying the exit review process and improving the relevant departments. Work efficiency and achieve sustainable supply of affordable housing.

\section{CONCLUSION}

Safeguarding people's equal enjoyment of the fruits of reform and development is one of the goals of China's economic development. The housing problem is not only an economic issue, but also a social issue. This paper analyzes the status quo of affordable housing from the perspective of supply side, analyzes the existing problems from the perspectives of supply demand, supply cost, spatial differentiation, supporting facilities and qualification review. This paper proposes five measures based on ensuring supply, reducing costs, promoting integration, improving quality and strengthening supervision. It can ensure the sustainability of the affordable housing system and provide scientific guidance for the government to plan more effective planning of affordable housing.

\section{REFERENCES}

[1] Li Ming. Research on the problems and countermeasures of the construction of affordable housing in China [J]. Jiangxi Building Materials. 2017 (23) 261-262. (In Chinese)

[2] Ma Enhui. Research on the Problems and Countermeasures of China's Safe Housing Reform_-Taking Shenzhen as an Example [D]. Nanchang University Master's Thesis, 2015. (In Chinese)

[3] Li Yining. Continue to promote supply-side structural reform [J]. China's circulation economy, 2017 (1) 4-6. (In Chinese)

[4] Li Chunli. Study on the Fair Distribution of Safe Housing in Shenzhen_-From the Perspective of Marxist Social Equity Theory [D] Master's Thesis of Shenzhen University, 2017.(In Chinese)

[5] Lu Changle. Shanghai will increase the supply of rented housing land. It is developing the rules for stock-to-rental housing $[\mathrm{N}] .21$ st Century Business Herald. 2017.10.13(007).(In Chinese) 